\section{PRICE LIST}

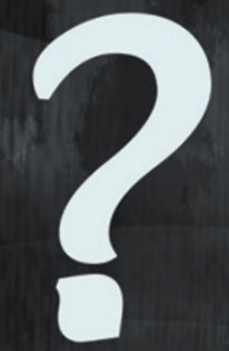

degree to which this report -

just like many others that have preceded it - oversimplifies what is a very complex and highly individual range of care and treatment options. It makes for a populist consumer story but it is ultimately unhelpful because it undermines the trust that the overwhelming majority of patients have in their dentist.

'General practitioners and their staff are responsible for explaining the complexities of the current three-band system to their patients, as well as dealing with any queries or complaints that result as a consequence. Patients, not surprisingly, find it difficult to understand and accept that you can have less treatment and still be expected to pay the same.'

\section{Dr Trevor Ferguson,}

Dean of the FGDP(UK):

'Confusion about treatment options, or about the costs of those options, should never be a barrier which stops patients from obtaining the dental advice and care that they need. We hope that the Which? investigation will draw attention to the complexity of providing mixed NHS and private care in the hope that these processes may be reviewed and simplified in future.'

\title{
SUGAR CONSUMPTION MUST BE REDUCED THROUGHOUT LIFE
}

The World Health Organisation (WHO) recommends a reduced intake of free sugars throughout life for both adults and children in their new guideline.

Following a consultation that ended in March 2014, the guideline Sugars intake for adults and children recommends that both adults and children reduce their intake of free sugars to less than $10 \%$ of total energy intake.

Free sugars include monosaccharides and disaccharides added to foods and beverages by the manufacturer, cook or consumer, and sugars naturally present in honey, syrups, fruit juices and fruit juice concentrates.

The recommendations are based on evidence reviewed regarding the relationship between free sugars intake and body weight and dental caries. Increasing or decreasing dietary sugars is associated with parallel changes in body weight. The recommendation to limit free sugars intake to less than $10 \%$ of total energy intake is based on evidence from observational studies of caries.

The WHO also suggests a further reduction of the intake of free sugars to below 5\% of total energy intake, in recognition that the negative health effects of caries are cumulative from childhood to adulthood - therefore even a small reduction in the risk of dental caries in childhood will be of significance in later life.

A publication date for the guideline has not yet been announced.

\section{Seeing red}

The London Eye is now sponsored by Coca-Cola. On the opening day of the rebranded visitor attraction, the Children's Food Campaign handed out 500 toothbrushes to visitors: 500 being the number of children admitted to hospitals in the UK each week for extractions.

Lydia Harris wrote the following letter to the $B D J$ Editor-inChief in response to the news.

Sir, on 17 January of this year the London Eye was rebranded the 'Coca-Cola London Eye'. With this rebrand, London's most iconic landmark has been illuminated red, the pods decorated with logos and staff uniform emblazoned with the Coca-Cola motif. Not surprisingly, this move has prompted some controversy within the health community. On the opening day, the Children's Food Campaign handed out toothbrushes to some of the first visitors, in an attempt to relay the message that sponsorship of such a tourist attraction by a sugary drinks manufacturer is wholly inappropriate.

Guidance from the World Health Organisation, issued in 2003, states that free sugars should make up less than 10\% of total energy consumed. ${ }^{1} \mathrm{~A}$ new draft guideline in fact suggests that this should be around 5\%, ${ }^{2}$ which equates to approximately 25 grams of sugar (with an average intake of 2,000 calories per day). With one $500 \mathrm{ml}$ bottle of CocaCola containing approximately $53 \mathrm{~g}$ of sugar and one $330 \mathrm{ml}$ can containing $35 \mathrm{~g}$, it is not surprising that sugar intake in all age groups exceeds current recommendations, with one of the key sources of sugar being soft drinks, particularly among teenagers. ${ }^{3}$

The following questions could then be posed: Does this type of advertising need more strict regulation, given the health consequences that increased consumption of this product could lead to? Would stopping this kind of sponsorship/advertising make a discernible difference to public health? Research suggests a link between sugary drinks marketing and sugar consumption, ${ }^{4,5}$ and in 2010 the World Health Organisation set out guidelines to 'ensure that children everywhere are protected against the impact of such marketing: ${ }^{6}$ Given Public Health England's best efforts to get people to 'Change4Life' (a campaign aimed to encourage swapping sugary drinks for sugarfree), it seems inappropriate for an iconic London landmark such as the (Coca-Cola) London Eye to be sponsored by, and indeed, advertising for, a corporate, sugary drinks giant, whose increased sales may worsen our public health and the costs to our NHS.

L. HARRIS, BRISTOL

1. World Health Organisation/Food and Agriculture Organization Diet, nutrition and the prevention of chronic diseases. Report of the Joint WHO/FAO Expert Consultation. Technical Report Series no. 916. Geneva 2003.

2. World Health Organisation. Draft Guideline: Sugars intake for adults and children. 2014.

3. Public Health England. Sugar reduction: responding to the challenge. Available at: https://www.gov.uk/government/uploads/system/uploads/ attachment_data/file/324043/Sugar_Reduction_Responding_to_the_ Challenge_26_June.pdf (accessed 11 February 2015).

4. Chandon $\bar{P}$, Wansink $B$. Does food marketing need to make us fat? A review and solutions. Nutr Rev 2012; 70: 571-593.

5. World Health Organisation. Reducing consumption of sugarsweetened beverages to reduce the risk of childhood overweight and obesity. Biological, behavioural and contextual rationale. Available at: http://www.who.int/elena/bbc/ssbs_childhood_obesity/en/ (accessed 28 January 2015).

6. World Health Organisation. A framework for implementing the set of recommendations on the marketing of foods and non-alcoholic beverages to children. 2012.

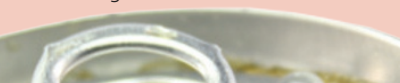

